\title{
Simulation Analysis for Electric Power Steering Control System Based On Permanent Magnetism Synchronization Motor
}

\author{
Shi Guobiao, a , Zhao Songhui ${ }^{2, \text { b }}$, Min Jun ${ }^{3, c}$ \\ ${ }^{1,2,3}$ School of Mechanical and Vehicular Engineering , Beijing Institute of Technology , Beijing \\ 10081,P.R.China \\ a'sgb@bit.edu.cn, ${ }^{\mathrm{b}} \mathrm{z} \_$songhui@163.com, ${ }^{\mathrm{c} m}$ _spring@163.com
}

Keywords: Electric Power Steering system, Permanent magnetism synchronization motor, Control, Simulation.

\begin{abstract}
In this paper the math model of Electric Power Steering system (EPS) based on Permanent Magnetism Synchronization Motor (PMSM) is built in MATLAB, which includes the simulation model of the steering mechanical system, PMSM and ECU of EPS. With the control strategy of direct-axis current on zero, SVPWM is used to drive PMSM. Based on the linear pattern assistant characteristic, this simulation model has emulated the system's performance on the condition of sine input of the steering wheel torque and achieves good real time control effect of assistant current and assistant torque output of PMSM.
\end{abstract}

\section{Introduction}

In the past century, automotive steering system updated constantly and more electronic control technology was used on it. Now the electrically controlled steering system on passenger car is mostly Electric Hydraulic Power Steering system (EHPS) or Electric Power Steering system (EPS). Comparing with EHPS, EPS is more environmentally friendly, safer and saves more energy. Currently Motor applied in EPS is divided into two main categories: brushed DC motor and permanent magnet brushless motor. According to the back-EMF and the supply current waveform, the permanent magnet brushless motor can be divided into brushless DC motor (BLDC) drove by square wave and permanent magnet synchronous motor (PMSM) drove by sine wave. Comparing with the same capacity ordinary motor, PMSM is smaller, lighter and has lower rotary inertia for rotor, which is suitable for high torque response and high performance requirement occasions, just like the EPS assistant motor in large and middle cars [1]. Considering the assistant motor on EPS is mostly brushed DC motor and domestic development about the control system for EPS with PMSM is not much, the research on this control system is valuable.

\section{EPS Basic Dynamic Model}

Fig.1 shows a reduced EPS dynamic model [2]. In Fig. 1, $\mathrm{J}_{\mathrm{s}}$ is the inertia of steering wheel and steering column, $\mathrm{K}_{\mathrm{s}}, \mathrm{B}_{\mathrm{s}}$ are the rigidity and deboost of steering column; $\mathrm{Km}$ is the rigidity of motor and reducer, $B_{m}, J_{m}$ are the friction factor and rotary inertia of assistant motor; $K_{r}, B_{r}$ are the linear rigidity and deboost of the pinion and rack; $m$ is the equivalent mass of the pinion and rack, and its value is the mass of rack plus the equivalent mass of pinion. $i_{m}$ is the reduction ratio of the reducer, $r_{p}$ is the pinion radius. $T_{d}, T_{m}$ are the input torque of steering wheel and output torque of motor separately, $\theta_{\mathrm{s}}, \theta_{\mathrm{r}}, \theta_{\mathrm{m}}$ are turn angles of steering wheel, steering column and motor. $\mathrm{x}$ is the displacement of rack. Combine with Fig. 1, the dynamic equation for EPS is obtained as follows:

The equation from steering wheel to steering column is:

$$
J_{s} \ddot{\theta}_{s}=T_{d}-K_{s}\left(\theta_{s}-\theta_{r}\right)-B_{s} \dot{\theta}_{s}
$$

The equation in the assistant section is:

$$
J_{m} \ddot{\theta}_{m}=T_{m}-K_{m}\left(\theta_{m}-i_{m} \theta_{r}\right)-B_{m} \dot{\theta}_{m}
$$

The equation in the section of rack and pinion is:

This work is partially supported by" the National High Technology Research and 


$$
m \ddot{x}=\frac{1}{r_{p}}\left[K_{m}\left(\theta_{m}-i_{m} \theta_{r}\right) i_{m}+K_{s}\left(\theta_{s}-\theta_{r}\right)\right]-B_{r} \dot{x}-K_{r} x
$$

On the basis of Eq. 1 and Eq. 3, build the mechanism part model for EPS in MATLAB, as shown in Fig. 2.



Fig.1 Structure of EPS system



Fig.2 Mechanism part simulation model

\section{PMSM’s Model}

There are several kinds of structure of PMSM, including surface convex, surface plug-in and built-in in accordance with the installation form of permanent magnets. Since the relative permeability of the permanent magnet material is very close to 1 , the surface bulge type is belong to implicit pole rotor structure, in which the direct axis has the same inductance as the quadrature axis in any rotor position. Permanent magnet pole of this structure is easy to implement optimized design and the magnetic flux intensity waveform in motor's air-gap could tend to a sine wave [3]. In consideration of easy to control, the EPS system uses a surface convex PMSM.

To establish a PMSM model, assume: (a) ignoring the saturation of the motor iron core and the influence of leakage magnetic flux; (b) excluding the eddy current and hysteresis losses in the motor; (c) the motor current is symmetrical three-phase sinusoidal current; (d) evenly distributed air gap between stator and rotor, the magnetic circuit independent of the rotor position, i.e. the inductance of each winding has no relation with the rotor position.

Based on the above assumptions, the stator voltage vector equation is as follow:

$$
U_{s}=R_{s} i_{s}+L_{s} \frac{d i_{s}}{d t}+\frac{d}{d t}\left(\varphi_{f} e^{j \theta_{r}}\right)
$$

Where $U_{s}, R_{s}, i_{s}, L_{s}, \varphi_{f}$ are voltage of stator terminal, resistance of stator winding, stator current, stator inductance and coupling magnetic linkage of the rotor magnet on the stator side. This is the voltage vector equation in the stator coordinate system, while the $\mathrm{d}-\mathrm{q}$ axis is more common when analyzing control method of the PMSM current. After the coordinate conversion, Eq. 5 in d-q axis is transformed from Eq. 4 as follow:

$$
\left\{\begin{array}{l}
u_{d}=R_{s} i_{d}+\frac{d}{d t} \varphi_{d}-\omega_{r} \varphi_{q} \\
u_{q}=R_{s} i_{q}+\frac{d}{d t} \varphi_{q}+\omega_{r} \varphi_{d} \\
\varphi_{d}=L_{d} i_{d}+\varphi_{f} \\
\varphi_{q}=L_{q} i_{q}
\end{array}\right.
$$

The electromagnetic torque of PMSM in $\mathrm{d}-\mathrm{q}$ axis is:

$$
T_{e}=p_{n}\left(\varphi_{d} i_{q}-\varphi_{q} i_{d}\right)=p_{n}\left[\varphi_{f} i_{q}+\left(L_{d}-L_{q}\right) i_{d} i_{q}\right]
$$

The equation of motor motion is: 


$$
J_{m} \frac{d \omega_{r}}{d t}=T_{e}-T_{L}-B_{m} \omega_{r}
$$

Where $\mathrm{u}_{\mathrm{d}}, \mathrm{u}_{\mathrm{q}}, \mathrm{i}_{\mathrm{d}}, \mathrm{i}_{\mathrm{q}}, \varphi_{\mathrm{d}}, \varphi_{\mathrm{q}}, \mathrm{L}_{\mathrm{d}}, \mathrm{L}_{\mathrm{q}}$ are stator winding voltage, current, magnetic linkage and inductance in d-q axis; $\varphi_{\mathrm{f}}$ is rotor magnetic linkage; $p_{\mathrm{n}}$ is the number of motor pole-pairs; $\omega_{\mathrm{r}}$ is the motor's angular frequency; $\mathrm{J}_{\mathrm{m}}, \mathrm{B}_{\mathrm{m}}$ are the friction factor and rotary inertia of assistant motor; $\mathrm{T}_{\mathrm{L}}$ is the load torque.

With Eq. 5, Eq. 6 and Eq. 7, invoke the PMSM simulation model and measurement model of motor parameters from Simulink, shown in Fig. 3.

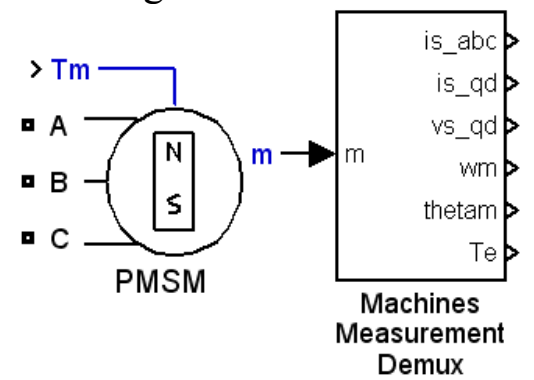

Fig. 3 Conjunction of PMSM model and measurement model

\section{ECU Model}

The function of ECU is to collect the torque sensor and the vehicle speed signal, select a suitable motor target current, execute the PID control by comparing with the feedback actual current, and then drive the PMSM with SVPWM actuating the inverter circuit.

EPS Assist Characteristic. The EPS assist characteristic is generally straight line, polygonal line or curve type. The straight line type is adopted here. As shown in Fig. 4[4].

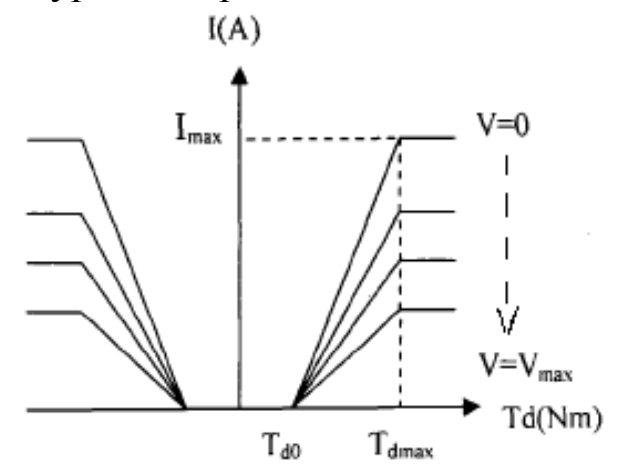

Fig.4 Straight line EPS assist characteristic

The above figure could be described by Eq. 8 as follow:

$$
i= \begin{cases}0 & \left(0 \leq T_{d} \leq T_{d 0}\right) \\ k(v) \times\left(T_{d}-T_{d 0}\right) & \left(T_{d 0} \leq T_{d} \leq T_{d \max }\right) \\ i_{\max } & \left(T_{d \max } \leq T_{d}\right)\end{cases}
$$

When the input torque of steering wheel $T_{d}$ is less than the threshold value $T_{d 0}$, in order to ensure good road feel in the small steering angle, the motor doesn't provide power. When $T_{d}$ is between $\mathrm{T}_{\mathrm{d} 0}$ and $\mathrm{T}_{\mathrm{dmax}}$, $\mathrm{i}$ goes a linear rising with $\mathrm{Td}$, and the ratio coefficient $\mathrm{k}(\mathrm{v})$ decreases with increasing vehicle speed. When $\mathrm{Td}$ is above $\mathrm{T}_{\mathrm{dmax}}$, the motor output a constant torque. As the speed increases, the maximum current of the assist motor shows a decreasing trend to ensure good road feel on steering wheel while speed increasing. When the vehicle speed is zero, the motor output the maximum current $I_{\max }$ to guarantee the portability in situ turning condition. In simulation model, torque signal comes from steering column just like practical application, which has a lag compared with steering wheel signal.

When building the model, the speed range with steering power is $0-140 \mathrm{~km} / \mathrm{h}$. While speed is above $140 \mathrm{~km} / \mathrm{h}$, EPS doesn't work to ensure good road feel in high speed situation. When the input 
torque of steering wheel is less than $1 \mathrm{Nm}$, the motor doesn't provide power. When the torque is above $7 \mathrm{Nm}$, the motor output a constant torque. Maximum motor current is 20A.

Model of SVPWM Waveform Modulation. Pulse width modulation (PWM) used in self-controlled frequency conversion speed adjustment system of PMSM is mostly Sinusoidal PWM (SPWM) or Space Vector PWM (SVPWM). SPWM is widely used now. While SVPWM has less harmonic content and switching loss, and higher utilization efficiency of the power supply voltage. Also the three-phase current of inverter output with SVPWM technology is closer to sine wave, which could generate a rotating magnetic field close to a circular form. With SVPWM the torque ripple of motor is reduced effectively. So it is more suitable for the EPS control system based on PMSM.

The principle of SVPWM modulation is to make the space voltage vector synthesized from the three-phase pulse instantaneous voltage output of inverter same as the expected space voltage vector. According to the different combination of power transistor state, eight basic space voltage vector's sizes and locations are got, shown in Fig. 5[5]. Two of them are zero vectors, in the center. The other six divide the space into six adjacent regions. Region number is shown in Fig. 5. SVPWM just combine the six vectors to get more power transistor states, so as to generate a similar circular magnetic field. When building the SVPWM model, the main work is to judge the sector of voltage vector and calculate the duration of each vector. By comparing with the triangular wave whose period and amplitude is $\mathrm{T}_{\mathrm{PWM}}$, the model output signals by selector switch. Furthermore, since SVPWM is used to drive motor, it's necessary to add the inverter model.

Based on the three above models, plus current control in direct axis, Park transformation and PID controller, the integral ECU model is built, seen in Fig. 6. The simulation parameters are defined as follows [2]:

Steering column part: $\mathrm{J}_{\mathrm{s}}=0.0012 \mathrm{~kg} \cdot \mathrm{m}^{2}, \mathrm{~B}_{\mathrm{s}}=0.26 \mathrm{Nm} \cdot \mathrm{rad}^{-1} \cdot \mathrm{s}, \mathrm{K}_{\mathrm{s}}=115 \mathrm{Nm} \cdot \mathrm{rad}^{-1}$; $\mathrm{K}_{\mathrm{m}}=125 \mathrm{Nm} \cdot \mathrm{rad}^{-1}, \mathrm{i}_{\mathrm{m}}=7.225 ; \mathrm{m}=32 \mathrm{~kg}, \mathrm{~B}_{\mathrm{r}}=653.203 \mathrm{~N} \cdot \mathrm{s}, \mathrm{K}_{\mathrm{r}}=91061.4 \mathrm{~N} / \mathrm{m}, \mathrm{r}_{\mathrm{p}}=0.007783 \mathrm{~m}$.

PMSM simulation parameter: $\mathrm{R}_{\mathrm{s}}=0.1 \Omega, \mathrm{L}_{\mathrm{s}}=0.1 \mathrm{mH}, \mathrm{p}_{\mathrm{n}}=4, \varphi_{\mathrm{f}}=0.0175 \mathrm{~Wb}, \mathrm{~J}_{\mathrm{m}}=0.0004704 \mathrm{~kg} \cdot \mathrm{m}^{2}$, $\mathrm{B}_{\mathrm{m}}=0.003339 \mathrm{Nm} \cdot \mathrm{rad}^{-1} \cdot \mathrm{s}$.

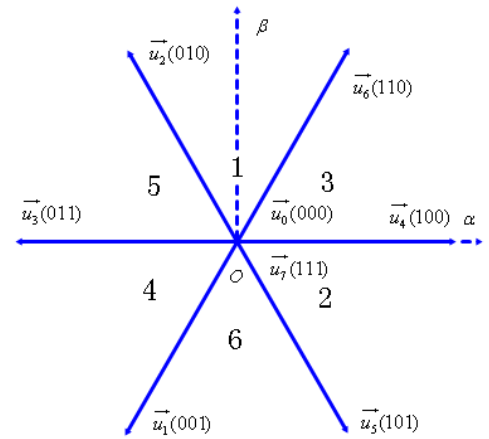

Fig.5 Basic space voltage vector



Fig.6 Integral ECU model

In the model above, since the motor is drove by SVPWM, the d-q axis current actually has much harmonic component. It is easy to bring oscillation into the system. So a filter whose cut-off frequency is $10 \mathrm{KHz}$ is added to the feedback current circuit. For the filter has a hysteretic effect on current, a filter with the same time constant is added to the target current in order to reduce the hysteretic influence. Besides, all parameters got from measurement module are electrical parameters, so the rotation angle and rotation speed signals measured should be multiplied by the motor pole number to get the motor's mechanical rotation angle and speed.

Integrating the mechanism part model in Fig. 2, PMSM model in Fig. 3 and ECU model in Fig. 6, the integral EPS simulation model is shown in Fig. 7 with the control strategy of $i_{d}=0$. 


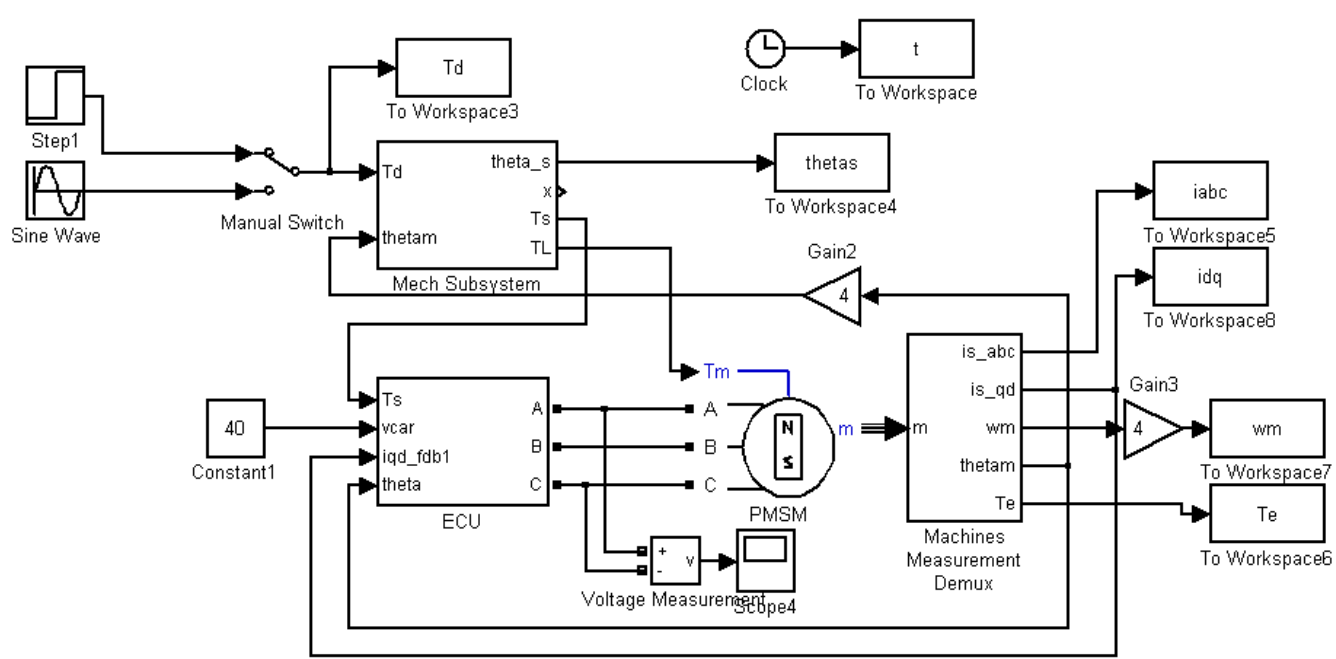

Fig. 7 EPS simulation model

\section{Analysis of Simulation Results}

The simulation analysis for this model is about the system reaction to the sine input of steering wheel torque and assist characteristic in still steering and driving steering condition. The simulation results are as follows.

Sine Input in Still Steering Condition. Assuming the input amplitude of steering wheel is $8 \mathrm{Nm}$, angular frequency is $\pi / 3$. Simulation results are shown in Fig. 8, Fig. 9, Fig. 10.

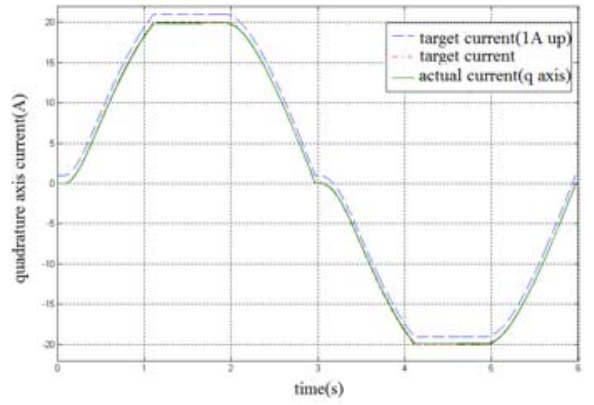

Fig. 8 quadrature axis current

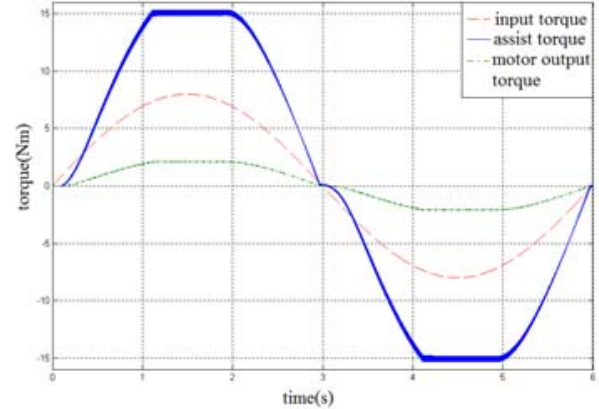

Fig. 9 output torque of motor

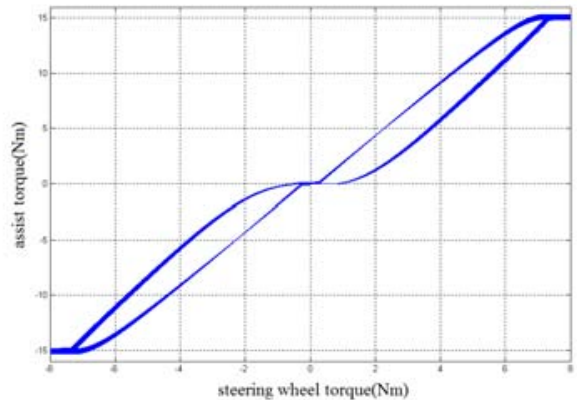

Fig. 10 relation between assist torque and input torque

Seen from the above simulation results, the ECU could control the motor current well in sine input, and the maximum assist torque is $15 \mathrm{Nm}$ in still steering condition, which satisfies the assist characteristic requirements. The torque ripple of the motor is in a small range of $+/-1.5 \%$.

Sine Input at the Speed of $40 \mathbf{k m} / \mathbf{h}$. Keeping on the sine input, set the speed on $40 \mathrm{~km} / \mathrm{h}$, simulation results are shown in Fig. 11, Fig. 12, Fig. 13 and Fig. 14. 




Fig. 11 quadrature axis current

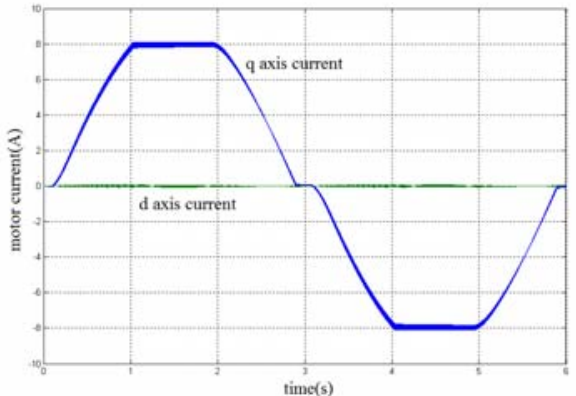

Fig. 13 actual d-q axis current of motor

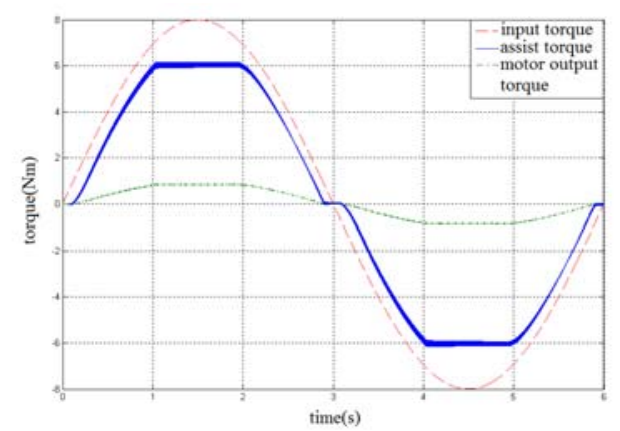

Fig. 12 output and assistant torque of motor

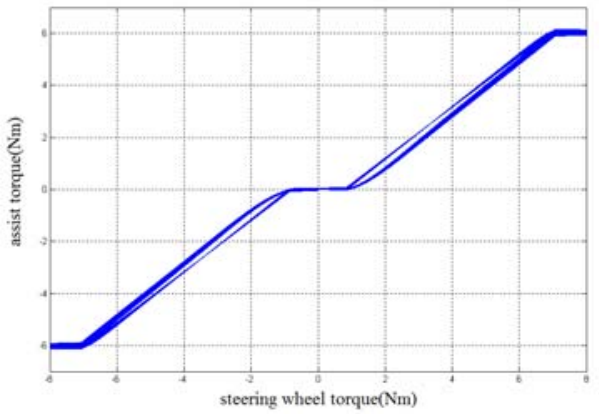

Fig. 14 relation between assist and input torque

Seen from the above figures, assist current and torque at $40 \mathrm{~km} / \mathrm{h}$ are lower than still steering condition, which is in keeping with the expected assist characteristic. Fig. 11 shows that quadrature axis current could follow up the target current well. Fig. 12 shows that assist torque has a small phase delay compared with input torque, meaning a good real time effect. The actual d-q axis current has much harmonic component, so it's important to add a filter on the feedback signal, see Fig. 13. Also, it satisfies the control strategy of $i d=0$, when q axis current keeps with target current.

\section{Conclusion}

In this paper, the model of EPS system based on PMSM is built to complete co-simulation of PMSM and control of EPS. The results prove the controllability of PMSM and the feasibility of control strategy. The ECU model lays the foundation for the development of ECU hardware and software. Also the EPS model provides a simulation and verification platform for the follow-up study on PMSM control methods.

\section{Acknowledgment}

This work was financially supported by the National High Technology Research and Development Program of China (863 Program): Research and Development of Electric Power Steering System for Electric Vehicle (Project Number 2011AA11A244), Development of Platform Technology of Electric Vehicle Power System (Project Number 2011AA11A223).

\section{References}

[1]J.Y.Liu:Simulation of PMSM torque control based on Matlab, Information Technology,04(2008) [2]J.P.Xu, R.He: Modeling and simulation of EPS, SAE-C2003E206, 654-661

[3]J.H.Ye:Principle and design of PMSM, Science Press(2007):122-228

[4]W.R.Shen: Development and experimental study of power steering system on electric bus, Beijing Institute of Technology, 2006

[5]G.J.Yang, L.Sun, N.Z.Cui and Y.P.Lu:Research on space vector pulse width modulation, Proceedings of The CSFE,21(2001) 